ISSN 0258-7122 (Print), 2408-8293 (Online)

Bangladesh J. Agril. Res. 44(1): 139-152, March 2019

\title{
PROFITABILITY ANALYSIS OF MANGO CULTIVATION AND ITS IMPACT ON FARMER'S LIVELIHOOD IN SOME AREAS OF BANGLADESH
}

\author{
M. S. RAHMAN ${ }^{1}$, M. KHATUN ${ }^{2}$, M. A. MONAYEM MIAH ${ }^{3}$
}

\begin{abstract}
The study was carried out to investigate profitability of mango farming and to assess the impact of BARI Aam-3 mango variety production on the farmer's livelihood in four mango growing districts namely Khagrachori, Bandorban, Naogaon, and Satkhira of Bangladesh during February to March, 2018. A total of 128 BARI Aam-3 growers were selected using multi-stage random sampling technique. Descriptive statistics and financial profitability analysis was used to analyze data. The net return for one hectare of mango orchard was Tk. 730233 for 6-7 years of BARI Aam-3 mango orchard. Net present value was estimated to Tk. 444397 for BARI Aam-3 which indicates that mango cultivation fetches higher returns. The estimated benefit cost ratio was 2.01 for BARI Aam-3 which ensures that investment in BARI Aam-3 is feasible for the mango farmers. The BARI Aam-3 mango cultivation was also found to be a profitable enterprise since internal rate of return was very high $(83.075 \%)$. The results also reveal that human capital increased by $54.34 \%, 68 \%$ and $60.54 \%$; physical capital increased by $48.17 \%, 58 \%$ and $50 \%$ as well as social capital increased by $28.50 \%, 43 \%$ and $45.95 \%$ of the small, medium and large farmers respectively due to cultivation of BARI Aam-3 mango variety. Therefore, it is highly recommended to spread the information of BARI Aam-3 cultivation as a profitable enterprise among the mango growers throughout the country.
\end{abstract}

Keywords: Mango, Profitability, Assets, livelihood, Bangladesh.

\section{Introduction}

Agriculture is the dominant economic activity in Bangladesh which comprises more than $15 \%$ of country's GDP and employs around $43 \%$ of labor force (BBS, 2017). Ensuring food and nutritional security and alleviating poverty is the prime concern of the present government. The Sustainable Development Goals (SDG) has reemphasized on the need of building more dependable food security system with increased productivity. Therefore, it is necessary to generate more diversified food with greater shares of fruit production. But production of fruits is still far behind the countries present requirement. About 78gm fruit is available

${ }^{1}$ Scientific Officer, Agricultural Economics Division, Bangladesh Agricultural Research Institute (BARI), Joydebpur, Gazipur-1701, Bangladesh, ${ }^{2}$ Assistant Professor, Department of Agricultural Finance, Bangladesh Agricultural University (BAU), Mymensingh-2202, Bangladesh, ${ }^{3}$ Principal Scientific Officer, Agricultural Economics Division, BARI, Joydebpur, Gazipur-1701, Bangladesh. 
per person in Bangladesh whereas 200gm is the daily requirement (BBS, 2017). Among the fruits in Bangladesh banana stands in the top position in terms of area coverage (32\%) and production (17\%) followed by mango (25\% area and $24 \%$ production) and pineapple (9\% area and 4\% production) (BBS, 2016). Mango (Mangifera indica $L$.) is recognized as the one of the choicest and well accepted fruit all over the world due to its attractive color, marvelous flavor, delicious taste and high nutritive value. It is a nutritionally important fruit being a good source of vitamin A, B \& C and minerals. Sugar constitutes main bulk of the carbohydrates and most of the soluble solids are found in ripe mango (Ravani and Joshi, 2013; Nigam et al., 2007). Area under mango production is fluctuated over the last decades whereas total production has been increased in Bangladesh. In 2004-05, mango was cultivated in 25055 hectares of land and yield was 26.43 ton/ha (BBS, 2008). Still then area coverage is being increased continuously with an upward movement of total production. In 2015-16, mango acreage was 37823 hectares with the highest level of production (1161685 metric tons) throughout the last decade with average yield of 30.71ton/ha (BBS, 2017). It is grown in most of the districts of Bangladesh. Bangladesh is the world's eighth largest mango producing country as it produces about $1,047,850$ tons of mangos every year which accounts for 3.9 percent of the world total mango production (Rahman and Khatun, 2018).

Area under mango production is fluctuated over the last decades whereas total production has been increased in Bangladesh. Figure 1 denotes that in 2004-05, mango was cultivated in 25055 hectares of land and yield was 26.43 ton/ha. Still then area coverage is being increased continuously with an upward movement of total production. In 2015-16, mango acreage was 37823 hectares with the highest level of production throughout the last decade i.e., 1161685 metric tons. The figure also shows that the yield of mango is increasing at an increasing rate during the year 2004-05 to 2014-15.

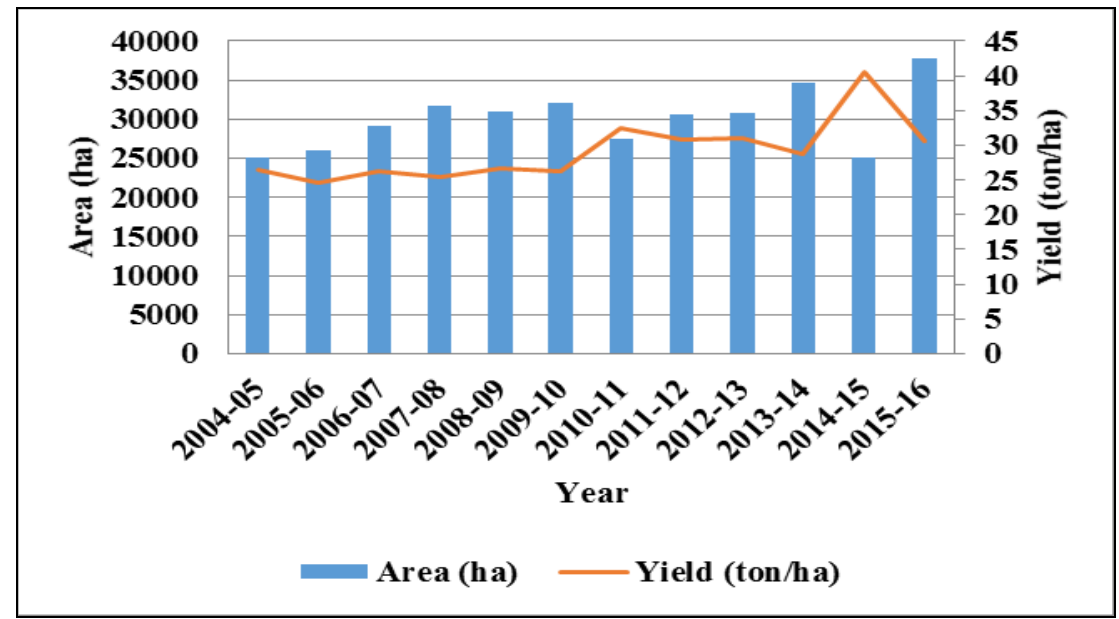

Fig. 1. Area and Yield of Mango Fruits in Bangladesh (Source: Various issues of BBS). 
But due to climatic context and soil advantages most of the best variety mango cultivation was limited to north-western and south-western districts of Bangladesh. The main source of income of this region is mango cultivation. With the innovation of modern developed mango variety, it is now cultivated commercially in other districts of Bangladesh. Bangladesh Agricultural Research Institute (BARI) is the leading organization to develop mango variety in Bangladesh. Since 1996 to 2015, it has developed 11 types of improved high yielding mango varieties (Azad et al., 2017).

Among the varieties BARI Aam-3 is an important innovation in Bangladesh. It is a hybrid mango variety, has been developed by crossing between Kiron (female) and Deshari (male) (Hossain et. al., 2003). At field level this variety is well known as Amropali or Aam Rupali or Rupali. Mainly it was developed in the Indian Agriculture Research Institute at Pusa, Delhi in 1971 (Wikipedia). Since then this mango has been introduced in the farms and orchards across India. After justifying its suitability in Bangladesh, it was approved for cultivation in 1996 in the name BARI Aam-3. BARI Aam-3 has been demonstrated very rapidly during the last decade. Because the climate and soil of Bangladesh are suitable for high yielding BARI Aam-3 cultivation and farmers get yield within three years of plantation with relatively less efforts. Shiblee (2015) conducted a study on assessing BARI released mango varieties at field level where he concluded that BARI Aam-3 was the best in all the firms under investigation in terms of sale of stions (stock + scion). Its cultivation has brought solvency to many people in Satkhira, Khagrachori, Naogaon and Bandarban districts of Bangladesh. But there is no in depth study on finding out profitability of growing mango specially BARI Aam-3 and its impact on farmer's livelihood in Bangladesh. The farmers need information regarding investment and returns from mango production business. Keeping in view the importance of mango in terms of area and production the present study investigates in determining cost of production and profitability of growing mango orchard. So the specific objectives of the study are:

i. To evaluate the economic profile of mango growers and

ii. To assess the assets of livelihood strategies of mango growers

\section{Methodology}

\section{Study area selection}

A preliminary survey was conducted in Sadar Upazila of Khagrachori district for pre-testing the survey schedule. Based on the preliminary survey, four BARI Aam-3 growing districts namely Khagrachori, Satkhira, Bandarban, and Naogaon were selected and two major BARI Aam-3 growing Upazilas from each district were purposively selected for selecting sample orchards. All the mango growers were randomly stratified into small ( $\leq 40$ trees), medium ( $41-\leq 79$ trees) and large ( $\geq 80$ trees). 


\section{Sampling technique adopted and way of sample selection}

Multi-stage random sampling technique was used to select the required mango growers. A total of 128 mango orchards were randomly selected for the study. The distribution of sample orchards is presented in the following Table 1.

Table 1. Distribution of sample orchards

\begin{tabular}{|c|c|c|c|c|c|}
\hline \multirow[b]{2}{*}{ Location } & \multicolumn{5}{|c|}{ BARI Aam-3 orchard (No.) } \\
\hline & $\begin{array}{c}\text { Up to } 1 \\
\text { year }\end{array}$ & 1-3 year & 3-5 year & $\begin{array}{l}\text { More than } \\
5 \text { year }\end{array}$ & Total \\
\hline \multicolumn{6}{|l|}{ 1.Khagrachori } \\
\hline - Khagrachori Sadar Upazila & 2 & 2 & 2 & 10 & 16 \\
\hline - Dighinala Upazila & 2 & 2 & 2 & 10 & 16 \\
\hline \multicolumn{6}{|l|}{ 2. Bandorbon } \\
\hline - Bandorban Sadar Upazila & 2 & 2 & 2 & 10 & 16 \\
\hline - Ali Kadam Upazila & 2 & 2 & 2 & 10 & 16 \\
\hline \multicolumn{6}{|l|}{ 3. Satkhira } \\
\hline - Satkhira Sadar Upazila & 2 & 2 & 2 & 10 & 16 \\
\hline - Kaliganj Upazila & 2 & 2 & 2 & 10 & 16 \\
\hline \multicolumn{6}{|l|}{ 4. Naogaon } \\
\hline - Naogaon Sadar Upazila & 2 & 2 & 2 & 10 & 16 \\
\hline - Sapahar Upazila & 2 & 2 & 2 & 10 & 16 \\
\hline Total & 16 & 16 & 16 & 80 & 128 \\
\hline
\end{tabular}

\section{Study period}

Primary data were collected from the respondents by using interview schedule during the month of January to March, 2018.

\section{Analytical Technique}

\section{Descriptive Statistics}

Descriptive statistics were used to analyze the data by sum, average and percentages.

\section{Statistical technique}

Growing fruit trees represent long term investment. Production of mango can be considered as a function of various inputs employed in the process of production. The farmers had to incur cost for different inputs such as human labor, machinery, fertilizer, insecticides etc. for cultivating mango in the orchard. The profitability of mango production was measured on the basis of Gross Return, Gross Margin and Net Return. At the same time capital budgeting was also done 
by calculating Net Present Value, Benefit Cost Ratio and Internal Rate of Return of the mango orchard. The discount rate was specified by assuming the opportunity cost of capital which is $12 \%$ for most of the developing countries (Gittinger, 1984).

\section{Livelihood analytical technique}

Livelihood pattern was measured by presenting the five types of capitals namely human capital, social capital, natural capital, physical capital and financial capital (DFID, 2000) which is known as assets pentagon. A sustainable livelihood is the outcome of inter and intra relationship between the components of these five livelihood assets/capitals. In this study, an attempt was made to measure the changes in assets position of the mango farmers for one year due to cultivation of BARI Aam-3 mango variety.

\section{Results and Discussions}

\section{Profitability of BARI Aam-3 Mango Farming}

Profit is a basic criterion for selecting an enterprise. The study found that farmer planted 100-120 trees per acre (100 decimal) of land in the sense that after 5-6 years they cut one of every three of the line in order to clear it for air and light. Farmers have the option to do intercrop with BARI Aam-3 mango orchard up to 3-4 years of age. Generally, after 4 years of mango tree farmers did not cultivate any kind of intercrop. The study also found that only $18 \%$ of the respondents do intercrop in one or two years in their orchard and they did it with different crops. Due to complexity in accounting costs and return of intercropping, the present study does not cover costs and return of intercropping in determining profitability of BARI Aam-3 mango farming.

It is evident from Table 3 that hired labor ranked the highest variable cost item of BARI Aam-3 mango orchard. The lowest used variable input was manures following by MoP among the chemical fertilizers. The per hectare total cost of BARI Aam-3 mango orchard from the establishment year to two years was estimated to Tk. 104211 where cost of saplings was the major cost item. Insecticides cost was not recorded during this period because there was no problem of insect. For the second section (2-3 years' trees) total cost was Tk. 82524 per hectare and the main component of variable cost was hired labor whereas the second most important one was insecticides. After that total cost was increased in ascending order. Fixed cost does not depend on the level of production. Only three items were considered as fixed cost for the mango orchard viz., family labour, interest on operating capital (IOC) and rental value of land in the study areas as indicating in Table 3. Considering all variable and fixed costs, total cost and net return was determined in the study areas. 


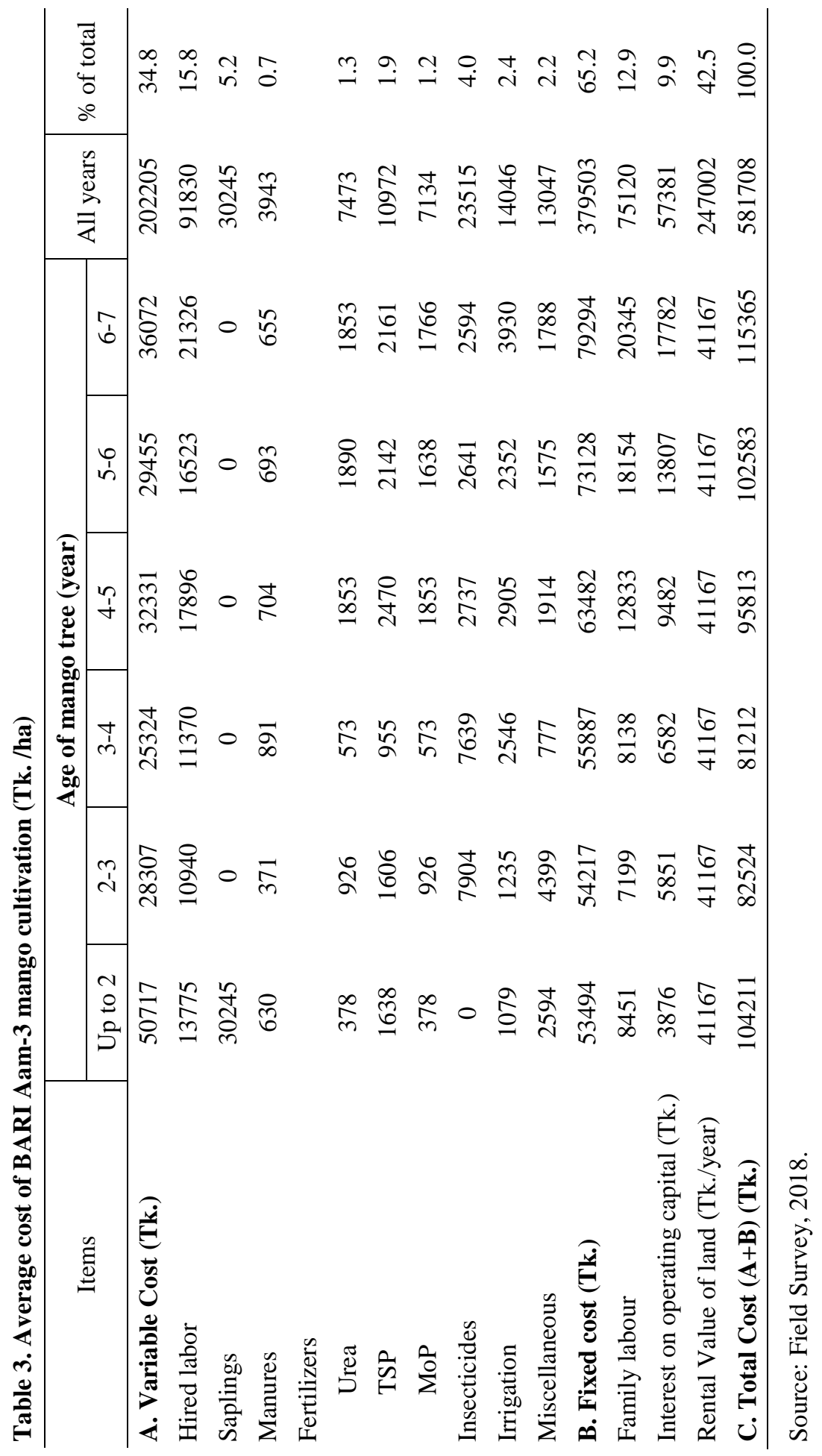




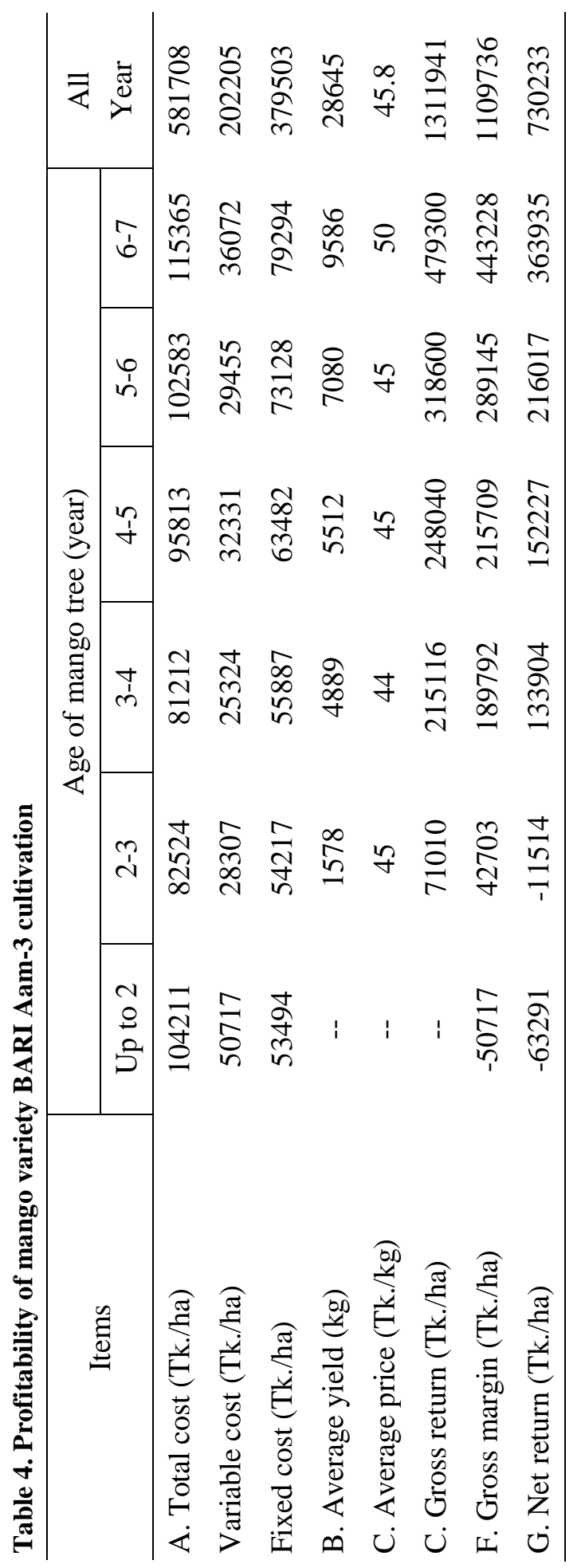


Per hectare average return of BARI Aam-3 mango orchards in the study areas are depicted in Table 4. Farmers told that they got fruits just after 2-3 years of plantation and this is unique only for BARI Aam-3 variety. So, gross margin and net return became negative up to 2 years of plant age as total cost was high enough at that time. Then net return increased substantially. Farmer told that in case of BARI Aam-3, fruit yield started decreasing drastically after 15 years of plant age. Per hectare average mango yield was found $5729 \mathrm{~kg}$ and gross return and net return was Tk. 1311941 and Tk. 730233 respectively from 2-3 years to 67 years of mango orchard.

\section{Capital Budgeting of BARI Aam-3 Mango Orchard}

Net present value (NPV): It is evident from Table 5 that NPV of BARI Aam-3 mango orchard is positive and greater than zero. Therefore, the mango production is an acceptance practice and feasible from financial point of view. Further, it also implies that the owner became able to increase his wealth by Tk. 444397 per hectare of mango production at the end of 6-7 years of plants age.

Benefit cost ratio (BCR): BCR was emerged to be 3.03 (Table 5) showing that investment in mango cultivation can be considered substantial and economically justifiable. It indicates that the mango growers earned a gross income of Tk. 2.01 by investing Tk. 1 per one hectare of mango orchard.

Internal rate of return (IRR): IRR was determined by following 'trial and error' approach at different discount rates. By using the formula mentioned in the methodology, IRR was calculated and it was $83.075 \%$. It is evident from Table 5 that IRR of BARI Aam-3 mango orchard stood at $83.075 \%$ which is sufficiently greater than existing bank interest rate. So, it assures that investing in BARI Aam-3 mango orchard was very much feasible and it ensured a reasonable profit for the investors.

Table 5. Per hectare rate of returns to investment on BARI Aam-3 mango orchard

\begin{tabular}{|c|c|c|c|c|}
\hline Year & $\begin{array}{l}\text { Gross cost } \\
(\mathrm{Tk})\end{array}$ & $\begin{array}{c}\text { Gross } \\
\text { benefit (Tk) }\end{array}$ & $\begin{array}{l}\text { Present worth of } \\
\text { gross cost at } 12 \%\end{array}$ & $\begin{array}{c}\text { Present worth of gross } \\
\text { benefit at } 12 \%\end{array}$ \\
\hline 0 & 104211 & 0 & 104211 & 0 \\
\hline 1 & 82524 & 71010 & 73682 & 63402 \\
\hline 2 & 81212 & 215116 & 64741 & 171489 \\
\hline 3 & 95813 & 248040 & 68198 & 176550 \\
\hline 4 & 102583 & 318600 & 65193 & 202476 \\
\hline \multirow[t]{5}{*}{5} & 115365 & 479300 & 65461 & 271968 \\
\hline & Total & & 441487 & 885885 \\
\hline & NPV & & 444397 & \\
\hline & BCR & & 2.01 & \\
\hline & IRR & & $83.075 \%$ & \\
\hline
\end{tabular}




\section{Impact of BARI Aam-3 mango cultivation on livelihood improvement}

Livelihood improvement of a farmer depends on various socioeconomic activities of the farmer as well as society. However, an attempt was made to measure the changes in assets position of the respondent farmers for one year due to cultivation of BARI Aam-3 variety.

\section{Human capital}

Appendix Table 1 shows that the access to human capital of small orchard owners increased by $54.34 \%$ due to cultivation of BARI Aam-3 especially education and training increased by $72.7 \%$ and $81.8 \%$ respectively. Appendix Table 1 represents that involvement in medium type BARI Aam-3 mango orchard production increases their access to human capital by $68 \%$ of which health and sanitation was increased by $100 \%$. At the same time education and nutrition status of the medium type BARI Aam-3 mango orchard owner increased by $80 \%$. Access to human capital by the large type BARI Aam-3 orchard owner was increased by $60.54 \%$ which also represents a good range of improvement in health and sanitation $(70.27 \%)$, education $(72.97 \%)$ and nutrition $(78.38 \%)$.

\section{Social capital}

Appendix Table 1 shows mostly a constant situation of the farmer's involvement in the social capital as they are mostly small mango orchard owner and their income may not support to build their strong social position. It shows only $28.8 \%$ of their access to social capital has increased. On the other hand, with the increase in the size of the BARI Aam-3 mango orchard farmers' access to social capital has increased slightly by $43.3 \%$ and $45.95 \%$ for the medium and large mango orchard owner respectively (Appendix Table 1). But in all the three types a positive movement was found in improvement of social respect and women empowerment.

\section{Natural capital}

Own cultivable land, cultivable land in lease system, using water (pond) and safe drinking water were increased compare to the other natural capital assets which is represented in Appendix Table. Majority of respondents had constant access to different types of natural capital. Most often some natural capital decrease for the respective respondents.

\section{Physical Capital}

The total access to physical capital was increased by $48.17 \%$ in case of small mango orchard owner while it was 58\% (Appendix Table 1) for medium mango orchard owner and $50 \%$ for large mango orchard owner. It means that with the 
investment in large size mango orchard brought out more positive output which tends to raise different kinds of physical assets. Number of brick built house was increased. These situations indicate the improvement of household condition of the respondent. The condition of other major components of housing as well as safe drinking water i.e., presence of tube well, electricity and sanitary toilet were also developed considerably. The number of using mobile phone increased tremendously for all the respondents. Some living assets like livestock such as cattle, goat, poultry and duck also were decreasing for the respective respondents. This happened because of lacking livestock grazing land in the study area.

\section{Financial capital}

In the case of small mango orchard owner, the status is more or less constant while in case of other two types it shows a gradual increase in all of the items of financial capital. The capital, cash in hand increased by $36.4 \%, 100 \%$ and $78.38 \%$ for the small, medium and large mango orchard owner respectively. Farmers' income was increased and they were able to save money and thereby donate more money than the past through raising their participation in mango production practices.

The shape of the pentagon (Figure 2) displayed schematically the variation in farmer's access to assets. It shows the change of livelihood status of BARI Aam3 farmers. Medium farmers were able to change all types of capital moderately than the small farmer. It is evident from the figure that livelihood status of large farmers has changed tremendously through BARI Aam-3 mango cultivation.

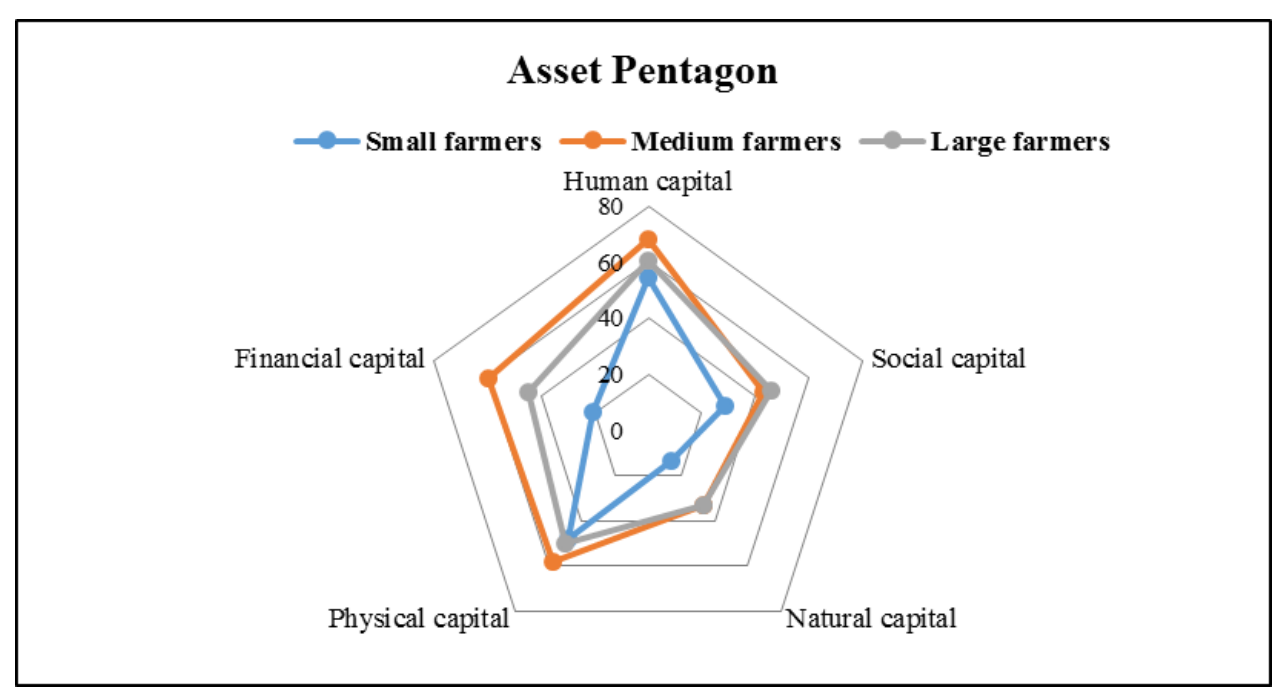

Fig. 2. Livelihood status of sample mango farm households

Table 10 shows that the significant improvement took place in farmer's livelihood due to the production of BARI Aam-3 variety in the study areas. Due 
to the adoption of BARI Aam-3 variety, small farmers were able to improve their human and physical capital by $54.34 \%$ and $48.17 \%$ respectively. In the case of medium farmer's, human, financial and physical capital was increased by $68 \%$, $60 \%$ and $58 \%$ respectively. But the adoption of BARI Aam-3 mango variety changed human capital and physical capital by $60.5 \%$ and $50 \%$ respectively for large farmer.

Table 10. Distribution of livelihood capital of BARI Aam-3 mango orchard owner

\begin{tabular}{l|ccc}
\hline \multirow{2}{*}{ Asset category } & \multicolumn{3}{c}{ Improvement of livelihoods (\%) } \\
\cline { 2 - 4 } & Small farmers & Medium farmers & Large farmers \\
\hline Human capital & 54.34 & 68.00 & 60.54 \\
Social capital & 28.50 & 43.30 & 45.95 \\
Natural capital & 13.65 & 33.30 & 33.33 \\
Physical capital & 48.17 & 58.00 & 50.00 \\
Financial capital & 20.47 & 60.00 & 44.60 \\
\hline
\end{tabular}

Source: Field Survey, 2018

\section{Conclusion and Recommendation}

Cultivation of BARI Aam-3 mango is profitable because it gives substantial higher gross return and net return. Human labor, cost of saplings, insecticides were the major cost items for mango production in the study areas. The rate of returns (i.e. BCR, NPV and IRR) indicated that BARI Aam-3 cultivation is profitable for the farmers. After adopting this variety all types of farmer are able to change their livelihood. They are able to increase their human, physical and social capital significantly. It signifies that, BARI Aam-3 mango production has a good potentiality in Bangladesh. So, to sustain the yield of BARI Aam-3, the combined efforts of concerned authorities are essential at the level of policy formulation. Besides, a proper initiative should be taken to record the information on cost and return and to disseminate this information throughout the country.

\section{References}

Azad, A.K., Goshami, B.K., Rahman, M.L., Malakar, P.K., Hasan, S., and Rahman, H.H. (2017). Edited KRISHI PROJUKTI HATBOI (Handbook on Agro-technology). $7^{\text {th }}$ edition, Bangladesh Agricultural Research Institution, Gazipur-1701, Bangladesh

Bangladesh Bureau of Statistics (BBS) (2018). Statistics and Informatics Division (SID), Ministry of Planning, Government of the People's Republic of Bangladesh

Bangladesh Bureau of Statistics (BBS) (2017). Statistics and Informatics Division (SID), Ministry of Planning, Government of the People's Republic of Bangladesh 
Department for International Development (DFID) (2000). Sustainable Livelihoods Guidance Sheets. http://www.livelihoods.org/info/info_guidancesheets.html (accessed: 05/06/2018)

Gittinger, J. (1984). Economic Analysis of Agricultural Projects. The Johns Hopkins University Press, $2^{\text {nd }}$ edition, Baltimore, USA. p. 361.

Hossain, Z., Quaiyum, M., Jakariya, M., and Akter, N. (2003). An assessment of the performance of BRAC nursery seedlings with special emphasis on Amrapali. Research and Evaluation Division, BRAC, 75 Mohakhali, Dhaka, Bangladesh

Nigam, S., Bhatt, D.K. and Jha, A. (2007). Different product of mango: the kind of fruits. Processed food Industry, 10(9): 32-40

Rahman, M. S. and Khatun, M. (2018). Adoption and farmer's perceptions of BARI Aam-3 Mango variety in selected areas of Bangladesh. Res. Agric. Livest. Fish. 5 (3): 301-311

Ravani, A., and Joshi, D.C. (2013). Mango and its by product utilization-a review. Trends in Post-Harvest Technology, Vol 1, Issue 1, pages 55-67

Shiblee, S.M.A. (2015). Assessment of BARI mango varieties in comparison with other varieties. Research abstracts of agricultural economics division 1978-2015. Agricultural Economics Division, Bangladesh Agricultural Research Institute (BARI), Joydebpur, Gazipur.

Wikipedia contributors. (2017, March 3). Amrapali (mango). In Wikipedia, The Free Encyclopedia. Retrieved 05:43, May 28, 2018, from https://en.wikipedia.org/w/index.php?title=Amrapali (mango)\&oldid=768340568. 


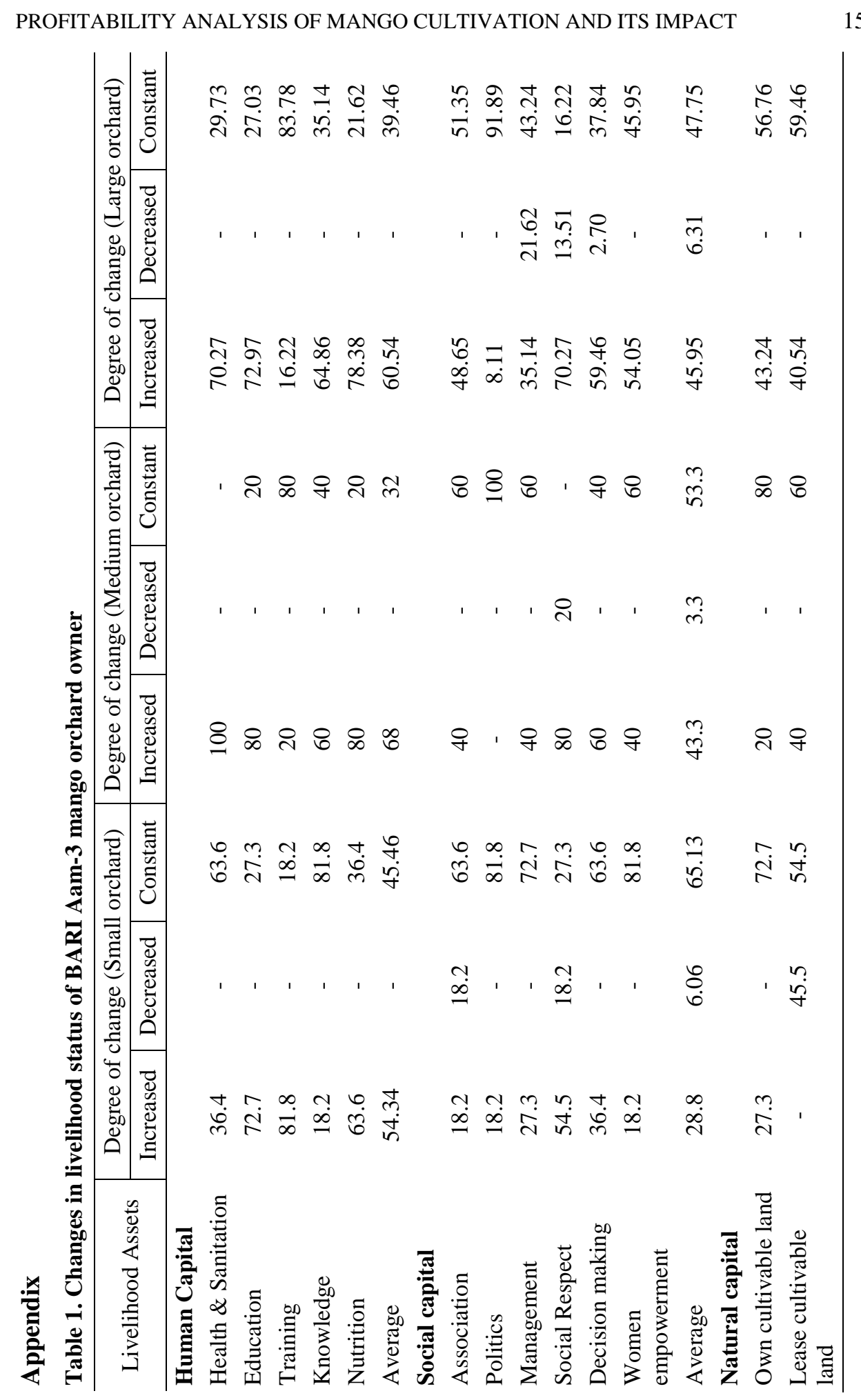




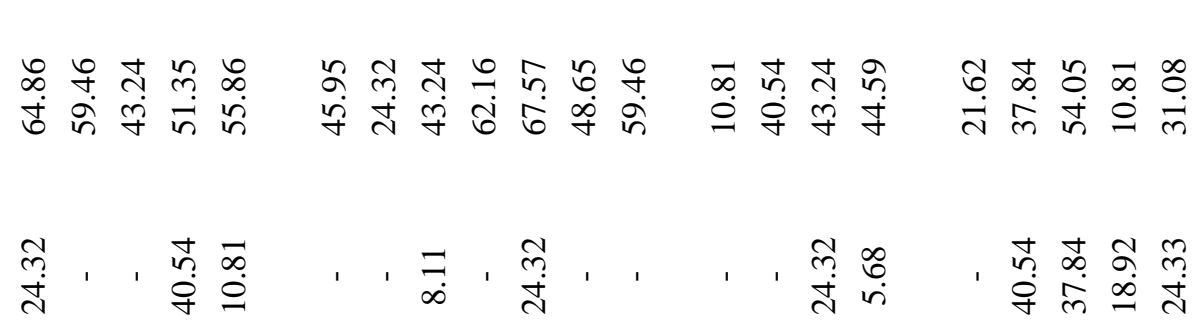

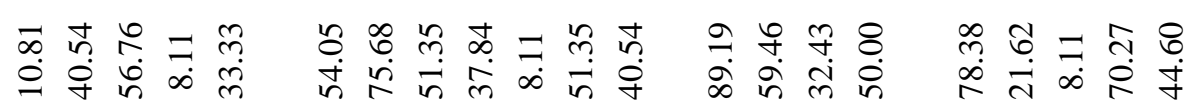

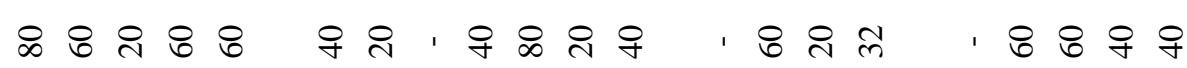
ㄱ. 1 유. , 年

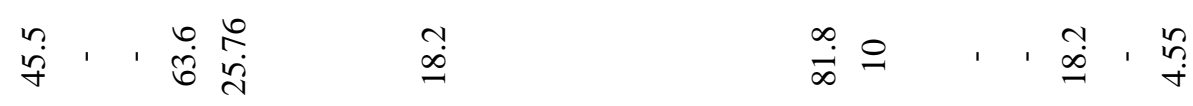

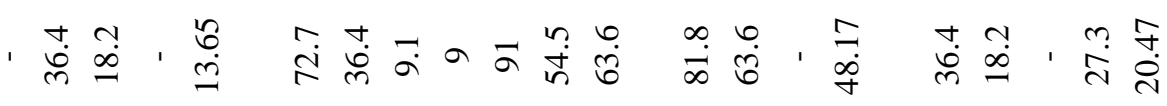

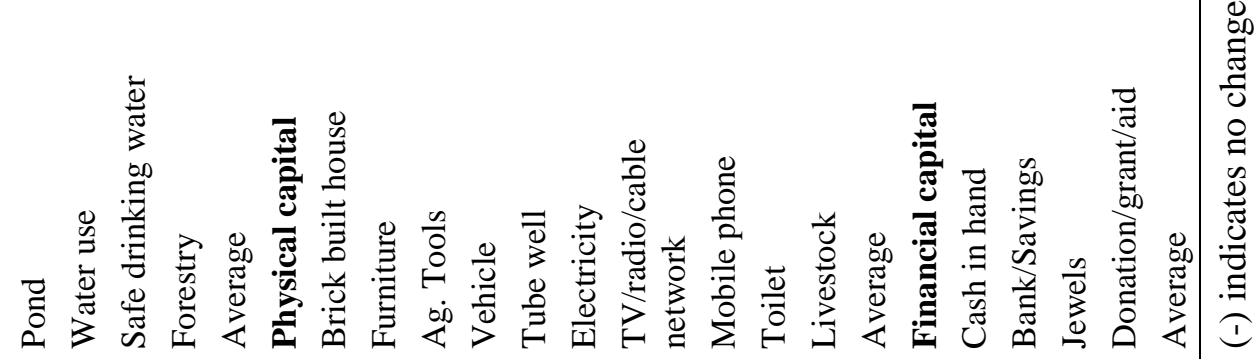

